\title{
CHEMOSPHERE
}

Chemosphere 61 (2005) 1505-1511

www.elsevier.com/locate/chemosphere

\section{Optimization of a pressurization methodology for extracting pore-water}

\author{
Isabel Lopes, Rui Ribeiro * \\ Instituto do Ambiente e Vida, Departamento de Zoologia, Universidade de Coimbra, Largo Marquês de Pombal, \\ 3004-517 Coimbra, Portugal
}

Received 7 June 2004; received in revised form 1 February 2005; accepted 21 April 2005

Available online 20 June 2005

\begin{abstract}
Sediment toxicity can be assessed by conducting pore-water toxicity assays with standard water column organisms. Several methods have been developed for sampling pore-water. Centrifugation and pressurization methods are recommended when large volumes of pore-water are required to perform toxicity assays. Nevertheless, these methods involve sediment transportation and storage in laboratory, which can alter sediment toxicity. Therefore, an extraction method for large volumes that could be employed in the field site would be highly desirable. This study aimed to optimize and further evaluate an existing sediment pressurizing device with low construction costs, easy to carry and operate in the field, and presenting minimal chemical reactivity. The latter characteristic was achieved by lining the device interior with Teflon, by using large pore filters $(50 \mu \mathrm{m})$, and by using an inert gas (nitrogen). Pore-water extraction efficiency and the toxicities of pore-water samples obtained by pressurization and by refrigerated centrifugation were compared. An artificial sediment ( $70 \%$ sand, $20 \%$ kaolin and 10\% alpha-cellulose) spiked with an alcohol (phenol), a surfactant (SDS), a metal (copper), an organophosphate pesticide (parathion), and a natural sediment contaminated with acid mine drainage, were assayed for toxicity using Microtox assays. Sediment pressurization was found to be as efficient to extract pore-water as centrifugation, being more cost effective and adequate for field use.
\end{abstract}

(c) 2005 Elsevier Ltd. All rights reserved.

Keywords: Squeezing device; Centrifugation; Interstitial water; Sediment; Toxicity; Microtox

\section{Introduction}

A great concern in ecotoxicology has been assigned to the evaluation of sediment toxicity, since sediments can act both as a sink and source of contaminants (Salomons et al., 1987; Doe et al., 2003). This comes because sediments are formed by the deposition of particles from

\footnotetext{
* Corresponding author. Tel.: +351 23982241; fax: +351 23986798.

E-mail address: rui.ribeiro@zoo.uc.pt (R. Ribeiro).
}

the overlaying water column. Chemicals dissolved in the water column and adsorbed to suspended particles will also be trapped in the bottom sediment. Within the sediment system, contaminants will tend to reach and equilibrium between the pore-water and the sediment particles, and, to elicit a toxic response, contaminants in sediments have to be sufficiently high for the equilibrium-partitioning concentrations in the pore-water to exceed toxic levels (Adams et al., 1985). Several works demonstrated that toxicity assays performed with pore-water are a promising tool to assess the toxicity of contaminated sediments (ASTM, 1990; DiToro 
et al., 1991; Carr and Chapman, 1992; Ozretich et al., 2000). In fact, for a number of compounds, such as non-polar organic contaminants, the key route of exposure is from the interstitial water (Adams et al., 1985).

Several methods have been employed to extract the sediment pore-water, including centrifugation (Ankley and Schubauer-Berigan, 1994; Carr and Chapman, 1995; Ozretich and Schults, 1998; Doig and Liber, 2000; Kelln et al., 2001), pressurization (Carr et al., 1989; Carr and Chapman, 1992, 1995; Kelln et al., 2001), suction (Bufflap and Allen, 1995; Carr and Chapman, 1995; Carr et al., 1996; Winger et al., 1998), and equilibration methods using dialysis membranes or fritted glass samplers (Jacobs, 2002; Lewandowski et al., 2002; Williamson et al., 2002). With the latter two methods (suction and dyalisis), the extraction of pore-water can be accomplished in place (Bufflap and Allen, 1995; Angelidis, 1997; Doe et al., 2003). The great advantage of such in situ methods lies on the fact that, as no remotion of the sediment is necessary, the sources of error (oxidation, sediment sampling, metal contamination, temperature artifacts, filtration), responsible for changing sediment toxicity, are reduced (Bufflap and Allen, 1995). Nevertheless, these methods have a significant disadvantage: the time needed to obtain the required volumes, namely to perform toxicity assays (in the case of dialysis it can last weeks) (Carr and Chapman, 1995; Bufflap and Allen, 1995; Doe et al., 2003). Thus, if the sources of error are minimized then ex situ (centrifugation and pressurization) methods could be as relevant as the in situ (suction and dialysis) ones. The development of a pore-water extraction device, for large volumes, that could be carried to the field would be highly desirable. Carr et al. (1989) presented a sediment squeezing device with pressurized air to extract, in the field, pore-water from marine sediments. This system used scuba tanks to deliver pressurized air, allowing the simultaneous pressurization of several samples in the field. The present study intended to optimize the methodology proposed by Carr et al. (1989), namely, by using a cheaper material (Plexiglas) instead of using Teflon (Carr et al., 1989; Carr and Chapman, 1995) or PVC (Carr and Chapman, 1995) and by using an anoxic atmosphere (nitrogen) to substitute the pressurized air, avoiding the oxidation of sediments and, thus, the alteration of toxicants' bioavailability. Furthermore, a second objective was to compare pore-water extraction efficiency and the toxicities of pore-water samples obtained by pressurization and centrifugation.

\section{Material and methods}

\subsection{Pressurizing device}

The pressurizing device consisted of a Plexiglas cylinder (length: $22.5 \mathrm{~cm}$; diameter: $9 \mathrm{~cm}$ ) topped (in both
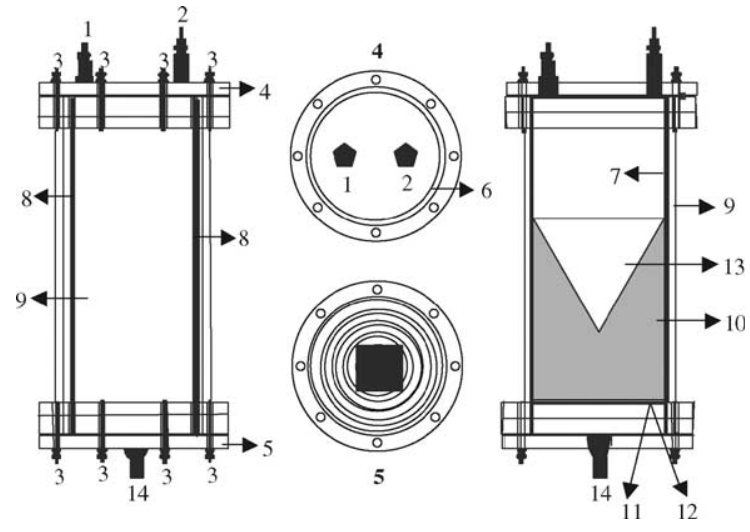

Fig. 1. Scheme of the pressurizing device. Legend: $1-$ Nitrogen inlet; 2 -pressure relieve fitting; 3 -nuts; 4 -upper plates; 5 bottom plates; 6-O-ring, 7-Teflon lining; 8-iron bars; 9Plexiglas cylinder; 10 -sediment; 11-Teflon mesh $(50 \mu \mathrm{m})$; 12-Teflon mesh $(200 \mu \mathrm{m}) ; 13$ - Teflon funnel; 14 - pore-water outlet.

ends) with Plexiglas endplates (Fig. 1). The top endplate held a pressure relief safety valve and a quick disconnect fitting to attach the nitrogen inlet tube made of inox steel (similar to those described by Carr et al. (1989)). The bottom endplate contained several interconnected concentric grooves to facilitate the flow of the pore-water to a central, inox steel made, outlet tube, from where the pore-water came out (Fig. 1). The interior of the tube was covered with Teflon film (Synthetica, Altena, Germany) in order to reduce the sorption of contaminants. Between the cylinder and the bottom endplate, two Teflon filters were fitted, with a mesh size of 50 and $200 \mu \mathrm{m}$. After introducing the sediment in the pressurizing device, a funnel made of a Teflon film was placed over the sediment to facilitate its pressurization. Pore-water samples were collected in previously acid rinsed polypropylene volumetric cylinders (Kartell, Noviglio, Italy).

\subsection{Artificial and natural sediments}

An artificial sediment (Ribeiro et al., 1999) composed by $70 \%$ of dry weight of acid-washed calibrated sand (Merck, Darmstadt, Germany), 20\% of kaolin (Sigma, St. Louis, MO, USA), and 10\% of alpha-cellulose (Sigma) was spiked with four different chemicals dissolved in nano-pure water. Spiking solutions were $2600 \mathrm{mg} / \mathrm{l}$ of phenol (Merck), $200 \mathrm{mg} / \mathrm{l}$ of sodium dodecyl sulfate (SDS) (Sigma), $350 \mathrm{mg} / \mathrm{l}$ of copper sulfate (Merck) and $5 \mu \mathrm{g} / \mathrm{l}$ of parathion (BDH, UK). Then $520 \mathrm{ml}$ of each spiking solutions were added to $800 \mathrm{~g}$ of dry and mechanically homogenized sediment. Sediments were again mixed mechanically for $1 \mathrm{~h}$. The day after, sediments were mixed again and separated into two parts with the same wet weight $(660 \mathrm{~g})$. One part was centrifuged and the other was pressurized. 
A natural sediment was sampled in an acid mine drainage contaminated effluent located at the extensively studied (Pereira et al., 1995, 1999, 2000; Lopes et al., 1999, 2004; Castro et al., 2003, Moreira-Santos et al., 2004) aquatic system of an abandoned cupric-pyrite mine (S. Domingos, SE Portugal). This aquatic system was chosen because the source of contamination $(\mathrm{pH}$ and heavy metals; $\mathrm{pH} \cong 2.1$, contaminated with $\mathrm{Fe}$, $\mathrm{Al}, \mathrm{Zn}, \mathrm{Cu}, \mathrm{Mn}, \mathrm{Co}, \mathrm{Ni}, \mathrm{Cd}, \mathrm{Pb}, \mathrm{Cr}$, As; in decreasing order; Pereira et al., 1995; Lopes et al., 1999; Pereira et al., 2000) is isolated and well identified, since no other contamination sources are known (e.g., pesticides, industrial discharges or urban runoff). After collection, the sediment was transported to the laboratory at low temperature $\left(4^{\circ} \mathrm{C}\right)$, in the dark and with zero headspace. The weight of natural sediment to obtain the pore-water was equal to that of artificial sediment. As with the spiked artificial sediments, $660 \mathrm{~g}$ (wet weight) of the natural sediment were separately subjected to centrifugation and pressurization.

\subsection{Pressurization versus centrifugation}

One of the two $660 \mathrm{~g}$ fractions of sediments was subjected to a refrigerated centrifugation $\left(-4^{\circ} \mathrm{C}\right)$ in $250 \mathrm{ml}$ polycarbonate bottles, in a Beckman J2-HS centrifuge (Beckman Instruments, Richmond, CA, USA). The other fraction was subjected to pressurization (in the pressurizing device, using nitrogen). With both methods, two sequential fractions of pore-water were obtained. With centrifugation method, the first fraction corresponded to a centrifugation for $30 \mathrm{~min}$ at $4000 \mathrm{rpm}$ (EPA, 1991). The same sediment sample was further centrifuged for $15 \mathrm{~min}$ at $9000 \mathrm{rpm}$ to obtain the second pore-water fraction. The corresponding water fractions were obtained by a 2 bar of nitrogen pressurization, until equal volumes to those obtained by centrifugation were extracted. The second fraction was obtained in the same manner as the first, submitting the same sediment to a second pressurization until a volume equal to the one from the second fraction extracted by centrifugation was extracted. Thus, the time of pressurization was not previously set, depending on the volume obtained at each time. All the pore-water fractions were left overnight under dark conditions at $4{ }^{\circ} \mathrm{C}$, after which were tested for toxicity. Filtration of the samples was not considered, aiming to avoid adsorption of contaminants to the filters (Ankley and Schubauer-Berigan, 1994; Adams et al., 2003).

For each pore-water fraction, conductivity (Wissenschaftlich Technische Werkstätten LF92, Weilhem, Germany) and pH (WTW 537) were measured after the overnight period. This settlement period allowed fine particles to settle and, thus, turbidity (measured with a $\mathrm{HACH}$ DR/200 spectrophotometer, Loveland, CO, USA; HACH, 1993) to decrease from $1075-8825$ to $\leqslant 1$
FTU. High turbidities could influence bioluminescence measurements (of the bacteria Vibrio fischerii) in the Microtox system (Microbics Corporation, 1992; Kross and Cherryholmes, 1993). Further chemical analyses were considered unnecessary since no concentrationeffect relationships were intended to be established, but solely the comparison of relative extraction efficiencies and pore-water toxicities between the two methods.

The pore-water extraction efficiency and its toxicity were compared between corresponding fractions (1st centrifugation versus 1 st pressurization and 2 nd centrifugation versus 2 nd pressurization). The toxicity of pore-water fractions was assessed within $24 \mathrm{~h}$ after extraction by running Microtox tests, following the Microbics corporation detailed protocol for Basic Test, with observations at 5, 15 and $30 \mathrm{~min}$, using a Microtox 500 Analyser (Microbics Corporation, 1992).

\subsection{Data analysis}

To compare conductivities, $\mathrm{pH}$ values and toxic units of pore-water fractions obtained by the two extraction methods, 2-tailed paired $t$-tests were used (Zar, 1996). Toxic units of Microtox results were determined by dividing 100 by the $\mathrm{EC}_{50}$ values (Microbics Corporation, 1992).

\section{Results}

\subsection{Physical parameters}

The $\mathrm{pH}$ values were similar between the pore-water extracted by pressurization and centrifugation (2-way paired $t$-test: $t_{9}=0.401, p=0.698$ ). Differences in the $\mathrm{pH}$ values between extraction methods never exceeded 0.1 units, for both the 1st and 2nd fractions. An exception occurred for copper sulphate: the pore-water of the 1 st fraction obtained by pressurization exhibited a $\mathrm{pH} 0.4$ units higher than the one obtained by centrifugation. Comparing the $\mathrm{pH}$ values between the 1 st and 2 nd fractions within each method, no significant differences were observed (2-tailed paired $t$-tests: $t_{4}=1.22, p=$ 0.289 and $t_{4}=1.52, p=0.203$, for pressurization and centrifugation, respectively). Differences in $\mathrm{pH}$ never exceeded 0.2 units, except for the pore-water of copper sulphate obtained by pressurization, where the 1 st fraction presented a $\mathrm{pH} 0.5$ units higher than the 2 nd fraction.

Similar results were obtained for conductivity values of pore-water extracted from the artificial sediment. No significant differences were observed between the porewater extracted by pressurization and centrifugation (2-tailed paired $t$-test: $t_{9}=0.787, p=0.452$ ); the highest difference registered between extraction methods never exceeded $2.5 \%$. Higher differences were observed in the 
Table 1

Conductivity $(\mu \mathrm{S} / \mathrm{cm}), \mathrm{pH}$ and volume $(\mathrm{ml})$ values measured in the two pore-water fractions, obtained either by pressurization or by centrifugation, after settling for an overnight period

\begin{tabular}{|c|c|c|c|c|c|}
\hline & Phenol & SDS & Copper sulphate & Parathion & Natural sediment \\
\hline \multicolumn{6}{|l|}{ Conductivity } \\
\hline 1st pressurized & 549 & 612 & 701 & 562 & 307 \\
\hline 1st centrifuged & 547 & 617 & 694 & 555 & 365 \\
\hline 2nd pressurized & 567 & 610 & 686 & 563 & 556 \\
\hline 2nd centrifuged & 557 & 595 & 688 & 549 & 440 \\
\hline \multicolumn{6}{|l|}{$p H$} \\
\hline 1st pressurized & 5.15 & 5.15 & 6.48 & 5.03 & 2.59 \\
\hline 1 st centrifuged & 5.23 & 5.24 & 6.09 & 5.02 & 2.58 \\
\hline 2nd pressurized & 5.38 & 4.95 & 5.85 & 4.83 & 2.54 \\
\hline 2nd centrifuged & 5.31 & 5.01 & 5.76 & 4.98 & 2.54 \\
\hline \multicolumn{6}{|l|}{ Volume } \\
\hline 1st fraction & 100 & 97 & 92 & 93 & 37 \\
\hline 2nd fraction & 35 & 27 & 35 & 40 & 12 \\
\hline Total volume & 135 & 124 & 127 & 133 & 49 \\
\hline
\end{tabular}

pore-water extracted from the natural sediment. In the 1st fraction, the pore-water extracted by centrifugation presented a conductivity $16 \%$ higher than the one from extracted by pressurization. In the 2nd fraction, the opposite was observed, the fraction obtained by pressurization exhibited a conductivity $28 \%$ higher than the one extracted by centrifugation. Within each method no significant differences were observed between the 1 st and 2nd fractions (2-tailed paired $t$-tests: $t_{4}=1.01, p=$ 0.372 and $t_{4}=0.601, p=0.580$, for pressurization and centrifugation, respectively) (see Table 1).

\subsection{Extraction efficiency}

The total volume of pore-water removed from the artificial sediment varied between 124 (SDS) to $135 \mathrm{ml}$ (phenol). The highest volume of pore-water was removed in the 1st fraction (average \pm SD: $95.5 \pm 3.7$ ), while a smaller part was obtained in the 2nd fraction $(34.3 \pm 5.4)$. With the natural sediment the amount of pore-water removed was smaller than with the artificial water $(49 \mathrm{ml}): 37 \mathrm{ml}$ were extracted in the 1 st fraction and $12 \mathrm{ml}$ in the 2 nd fraction.

Comparing the time needed to obtain the same volume of pore-water, pressurizing the sediment with an increasing pressure until 2 bar of nitrogen allowed a faster extraction of the same pore-water volume than centrifugation, both with the artificial and natural sediments. To extract the 1st fraction of pore-water by centrifugation, $30 \mathrm{~min}$ were used for all tested sediments, while only 2 min $( \pm 0.7)$ of pressurization were needed for the artificial sediments and $11 \mathrm{~min}$ for the natural sediment. The extraction of the 2 nd fraction by centrifugation took $15 \mathrm{~min}$, while only $4.6 \mathrm{~min}( \pm 1.1 \mathrm{~min})$ and $7 \mathrm{~min}$ were needed to extract the same volume by pres- surization for the artificial and natural sediments, respectively.

\subsection{Microtox basic test}

Toxic units calculated for each extraction method were similar both after 5, 15 and $30 \mathrm{~min}$ of exposure, indicating that the toxicity of pore-water extracted by pressurization and by centrifugation was the same (Table 2). No significant differences were observed between methods and between fractions, within the same method, in the three observation periods (paired $t$-tests: $t_{4}<1.86 ; p \geqslant 0.064$ ).

\section{Discussion}

Conductivity and $\mathrm{pH}$ values were similar between the two methods, indicating that desorption from particles occurred in an identical manner during both extraction processes. Howes et al. (1985) compared pore-water constituents collected by pressurization and centrifugation and found that the chemical components in the pore-water were not affected by the extraction process. Furthermore, Ankley and Schubauer-Berigan (1994) also compared $\mathrm{pH}$ and conductivity of pore-water samples obtained by centrifugation and pressurization and found no significant differences between them.

The higher conductivity registered in the second fraction of pore-water extracted from the natural sediment could be due to a difference in the mixture of ions in the extracted pore-water. The natural sediment contaminated with acid mine drainage contains extremely high concentrations of many heavy metals (Pereira et al., 1995) and hydrogen ions. Probably, in the second frac- 
Table 2

Toxic units (TU) for the Microtox tests obtained at 5, 15 and $30 \mathrm{~min}$ of exposure for the 1st and 2nd fractions obtained by centrifugation and by pressurization

\begin{tabular}{|c|c|c|c|c|c|}
\hline & Phenol & SDS & Copper sulphate & Parathion & Natural sediment \\
\hline \multicolumn{6}{|l|}{$5 \min$} \\
\hline 1st pressurized & 22.0 & 11.2 & 1.41 & 2.95 & $<1$ \\
\hline 1st centrifuged & 25.3 & 11.7 & 2.48 & 3.98 & $<1$ \\
\hline 2nd pressurized & 23.2 & 14.1 & 1.68 & 3.46 & 16.0 \\
\hline 2nd centrifuged & 20.0 & 11.2 & 1.81 & 2.26 & $<1$ \\
\hline \multicolumn{6}{|l|}{$15 \mathrm{~min}$} \\
\hline 1st pressurized & 21.1 & 24.7 & 2.62 & - & 9.90 \\
\hline 1st centrifuged & 23.5 & 25.8 & 4.72 & 5.24 & 7.81 \\
\hline 2nd pressurized & 18.5 & 25.3 & 3.23 & 4.58 & 14.3 \\
\hline 2nd centrifuged & 19.6 & 20.0 & 5.76 & 3.06 & 10.1 \\
\hline \multicolumn{6}{|l|}{$30 \mathrm{~min}$} \\
\hline 1st pressurized & 21.8 & 28.3 & 4.29 & 4.83 & 11.8 \\
\hline 1st centrifuged & 24.3 & 31.4 & 7.14 & 7.14 & 10.7 \\
\hline 2nd pressurized & 20.4 & 33.3 & 5.40 & 5.97 & 19.1 \\
\hline 2nd centrifuged & 18.8 & 25.4 & 6.58 & 4.14 & 13.1 \\
\hline
\end{tabular}

tion of pore-water, the concentration of heavy metals was higher than in the first fraction. This can also be linked with the composition of the sediments; the natural sediment was almost exclusively comprised of silt and clay (Castro et al., 2003), which contains particles with a high grain size: surface ratio, thus binding more heavy metals. Probably, many of those metal ions, bound to the clay particles, were released in the second fraction. This difference in particle contents can also explain the larger volume of pore-water obtained with the artificial sediment. The water located between the clay particles is more difficult to remove than the water located between the sand particles. Carr et al. (1989) also noticed that the time he required to extract pore-water from a sandy sediment was smaller than from clay or silt sediments. Thus, in the same time and with the same pressure, the amount of pore-water removed from the artificial sediment will be higher than from the natural sediment, as occurred in this study.

The toxicity of pore-water extracted by centrifugation and by pressurization was always similar indicating that the desorption processes of the chemicals from the sediment particles was identical with the two extraction methods. Furthermore, the toxicity presented by the two fractions, within the same process, was also similar, indicating that the pore-water and the sediment were in equilibrium; after extracting the first pore-water fraction no release of chemicals from the sediment particles seemed to occur. Thus, it seems that the first fraction is an acceptable sample to assess sediment toxicity.

This study showed that for the tested chemicals and for the natural sediment (contaminated with acid mine drainage), pore-water toxicity and toxicants' bioavailability were not influenced by the extraction methods (centrifugation and pressurization). Therefore, other factors, such as the volume of pore-water and easiness of extraction become more important when selecting the most adequate extraction method. The sediment pressurizing device was found to be as efficient as the centrifuge to extract pore-water, though the former required less time to obtain the same water volume. Similar toxicities, for both pore-water fractions, from the two methods attested the validity of this optimized sediment pressurizing device. The pressurizing device presents some advantages over the centrifugation method, since, as suggested by Carr et al. (1989), the pressurizing device can be used at the sampling site with a Scuba tank. This allows pore-water to be obtained immediately. The use of Scuba tank linked to several pressurizing devices in series will allow large volumes of pore-water from multiple samples to be collected as previously reported (Carr et al., 1989).

In conclusion, the pressurizing device proposed in this study is advantageous, since it is constructed with cheap material, facilitating its acquisition. The gas (nitrogen) here used to pressurize the sediment is inert, thus minimizing chemical alterations in pore-water due to oxidation.

\section{Acknowledgement}

Authors wish to thank Olímpia Sobral for technical assistance.

\section{References}

Adams, W.J., Kimerle, R.A., Mosher, R.G., 1985. Aquatic safety assessment of chemicals sorbed to sediments. In: 
Cardwell, R.D., Purdy, R., Bahner, R.C. (Eds.), Aquatic Toxicology and Hazard Assessment: Seventh Symposium. ASTM STP854. American Society for Testing and Materials, Philadelphia, PA, pp. 429-453.

Adams, W.J., Burgess, R.M., Gold-Bouchot, G., LeBlanc, L., Liber, K., Williamson, B., 2003. Porewater chemistry: effects of sampling, storage, handling, and toxicity testing. In: Carr, R.S., Nipper, M. (Eds.), Porewater Toxicity Testing: Biological, Chemical, and Ecological Considerations. Society of environmental toxicology and chemistry, Pensacola, USA, pp. 95-124.

Angelidis, T.N., 1997. Comparison of sediment pore water sampling for specific parameters using two techniques. Water Air Soil Pollut. 99, 179-185.

Ankley, G.T., Schubauer-Berigan, M.K., 1994. Comparison of techniques for the isolation of sediment pore water for toxicity testing. Arch. Environ. Contam. Toxicol. 27, 507512.

ASTM, 1990. Standard guide for collection, storage, characterization and manipulation of sediments for toxicological testing. E 1391-90. Annual Book of American Society for Testing and Materials Standards, Philadelphia, PA, USA.

Bufflap, S.E., Allen, H.E., 1995. Sediment pore water collection methods for trace metal analysis: a review. Water Res. 29, 165-177.

Carr, R.S., Chapman, D.C., 1992. Comparison of whole sediment and porewater toxicity tests for assessing the quality of estuarine sediments. Chem. Ecol. 7, 19-30.

Carr, R.S., Chapman, D.C., 1995. Comparison of methods for conducting marine and estuarine sediment porewater toxicity tests - extraction, storage, and handling techniques. Arch. Environ. Toxicol. Chem. 28, 69-77.

Carr, R.S., Williams, J.W., Fragata, C.T.B., 1989. Development and validation of a novel marine sediment pore-water toxicity test with the polychaete Dinophilus gyrocilliatus. Environ. Toxicol. Chem. 8, 533-543.

Carr, R.S., Long, E.R., Herbert, L.W., Chapman, D.C., Thursby, G., Sloane, G.M., Wolfe, D.A., 1996. Sediment quality assessment studies of Tampa bay, Florida. Environ. Toxicol. Chem. 17, 1218-1231.

Castro, B.B., Guilhermino, L., Ribeiro, R., 2003. In situ bioassay chambers and procedures for assessment of sediment toxicity with Chironomus riparius. Environ. Pollut. $125,325-335$.

DiToro, D.M., Zarba, C.S., Hansen, D.J., Berry, W.J., Swartz, R.C., Cowan, C.E., Pavlou, S.P., Allen, H.E., Thomas, N.A., Paquin, P.R., 1991. Technical basis for establishing sediment quality criteria for nonionic organic chemicals using equilibrium partitioning. Environ. Toxicol. Chem. 10, 1541-1583.

Doe, K.G., Burton Jr., G.A., Ho, K.T., 2003. Porewater toxicity testing: an overview. In: Carr, R.S., Nipper, M. (Eds.), Porewater Toxicity Testing: Biological, Chemical, and Ecological Considerations. Society of Environmental Toxicology and Chemistry, Pensacola, USA, pp. 125-141.

Doig, L., Liber, K., 2000. Dialysis minipeeper for measuring pore-water metal concentrations in laboratory sediment toxicity and bioavailability tests. Environ. Toxicol. Chem. 19, 2882-2889.

EPA, 1991. Sediment toxicity indentification: phase I (characterization), phase II (identification) and phase III (confir- mation) modifications of effluent procedures. National Effluent Toxicity Assessment Center. Technical Report, EPA/600/6-91/007. United States Environmental Protection Agency, Washington DC, USA.

HACH, 1993. DR/2000 Spectrophotometer Handbook. HACH Co., Loveland, CO, USA.

Howes, B.L., Dacey, J.W.H., Wakeham, S.G., 1985. Effects of sampling technique on measurements of porewater constituents in salt marsh sediments. Limnol. Oceanogr. 30, 221227.

Jacobs, P.H., 2002. A new rechargeable dialysis pore water sampler for monitoring sub aqueous in-situ sediment caps freshwater lakes: results from a novel dialysis sampler. Environ. Sci. Technol. 36, 2039-2047.

Kelln, C.J., Wassenaar, L.I., Hendry, M.J., 2001. Stable isopopds (delta O-18, delta $\mathrm{H}-2$ ) of pore waters in clay-rich aquitards: a comparison and evaluation of measurement techniques. Ground Water Monit. Rem. 21, 108116.

Kross, B.C., Cherryholmes, K., 1993. Toxicity screening of sanitary landfill leachates: a comparative evaluation with Microtox ${ }^{\circledR}$ analysis, chemical, and other toxicity screening methods. In: Richardson, M. (Ed.), Ecotoxicology Monitoring. VCH, NewYork, NY, USA, pp. 225-247.

Lewandowski, J., Ruter, K., Hupfer, M., 2002. Two-dimensional small-scale variability of pore water phosphate in freshwater lakes: results from a novel dialysis sampler. Environ. Sci. Technol. 36, 2039-2047.

Lopes, I., Baird, D.J., Ribeiro, R., 2004. Genetic determination of tolerance to lethal and sublethal copper concentrations in field populations of Daphnia magna. Arch. Environ. Contam. Toxicol. 46, 43-51.

Lopes, I., Gonçalves, F., Soares, A.M.V.M., Ribeiro, R., 1999. Ecotoxicological tools in the remediation of acid mine drainage. Toxicol. Environ. Chem. 70, 441-460.

Microbics Corporation, 1992. Microtox ${ }^{\circledR}$ Manual, A Toxicity Testing Handbook. Carlsbad, CA, USA.

Moreira-Santos, M., Soares, A.M.V.M., Ribeiro, R., 2004. An in situ bioassay for freshwater environments with the microalga Pseudokirchneriella subcapitata. Ecotoxicol. Environ. Saf. 59, 164-173.

Ozretich, R.J., Schults, D.W., 1998. A comparison of interstitial water isolation methods demonstrates centrifugation with aspiration yields reduced losses of organic constituents. Chemosphere 36, 603-615.

Ozretich, R.J., Ferraro, S.P., Lamberson, J.O., Cole, F.A., 2000. Test of $\Sigma$ polycyclic aromatic hydrocarbon model at a creosote-contaminated site, Elliot Bay, Washington, USA. Environ. Toxicol. Chem. 19, 2378-2389.

Pereira, E.G., Moura, I., Costa, J.R., Mahony, J.D., Thomann, R.V., 1995. The S. Domingos Mine: a study of heavy metals contamination in the water column and sediments of the Chança river basin by discharge from an ancient cupriferous pyrite mine (Portugal). Mar. Freshwater Res. 46, 145151.

Pereira, A.M.M., Soares, A.M.V.M., Gonçalves, F., Ribeiro, R., 1999. Test chambers and test procedures for in situ toxicity testing with zooplankton. Environ. Toxicol. Chem. 18, 1956-1964.

Pereira, A.M.M., Soares, A.M.V.M., Gonçalves, F., Ribeiro, R., 2000. Water-column, sediment, and in situ chronic 
bioassays with cladocerans. Environ. Ecotoxicol. Saf. 47, 27-38.

Ribeiro, R., Kelly, L.A., Gonçalves, F., Burton Jr., G.A., Soares, A.M.V.M., 1999. New artificial sediment for Chironomus riparius toxicity testing. Bull. Environ. Contam. Toxicol. 63, 691-697.

Salomons, W., de Rooij, N.M., Kerdijk, H., Bril, J., 1987. Sediments as a source of contaminants. Hydrobiologia 149, $13-30$.
Williamson, K.S., Petty, J.D., Huckins, J.N., Lebo, J.A., Kaiser, E.M., 2002. Sequestration of priority pollutants PAHs from sediment pore-water employing semipermeable membrane devices. Chemosphere 49, 717-729.

Winger, P.V., Lasier, P.J., Jackson, B.P., 1998. The influence of extraction procedure on ion concentrations in sediment pore water. Arch. Environ. Contam. Toxicol. 35, 8-13.

Zar, J.H., 1996. Biostatistical Analysis. Prentice-Hall, New Jersey, NJ, USA. 